\title{
Control of oncogenesis and cancer therapy resistance by the transcription factor NF- $\kappa B$
}

\author{
Albert S. Baldwin \\ Lineberger Comprehensive Cancer Center, University of North Carolina School of Medicine, Chapel Hill, North Carolina 27599, USA. \\ Phone: (919) 966-3652; Fax: (919) 966-0444; E-mail: jhall@med.unc.edu.
}

The transcription factor NF- $\mathrm{KB}$ is well established as a regulator of genes encoding cytokines, cytokine receptors, and cell adhesion molecules that drive immune and inflammatory responses (1). More recently, NF- $\mathrm{KB}$ activation has been connected with multiple aspects of oncogenesis, including the control of apoptosis, the cell cycle, differentiation, and cell migration. Additionally, activation of NF- $\mathrm{\kappa B}$ in cancer cells by chemotherapy or by radiation can blunt the ability of the cancer therapy to induce cell death. Below, I describe the compelling evidence that NF- $\mathrm{KB}$ is dysregulated in many forms of cancer and that its inhibition is a logical therapy for certain cancers and for adjuvant approaches to cancer therapy.

\section{Regulation of NF-KB activity}

Presently, there are five known members of the NF- $\kappa B$

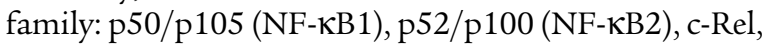
RelB, and p65 (RelA), each distinguished by its Rel homology domain, the portion of the protein that controls DNA binding, dimerization, and interactions with inhibitory factors known as the IKB proteins (reviewed in ref. 1$)$. The various $\mathrm{I} \kappa \mathrm{Bs}(\mathrm{I} \kappa \mathrm{B} \alpha, \mathrm{I} \mathrm{I} \mathrm{B} \beta$, and $\mathrm{I} \kappa \mathrm{B} \varepsilon)$ bind $\mathrm{NF}-\mathrm{KB}$ proteins and, in general, act to retain the latter molecules in the cytoplasm (1). Another member of the $\mathrm{I} \kappa \mathrm{B}$ family is Bcl-3, which interacts with p50 and p52 subunits of NF- $\mathrm{KB}$ to stimulate transcription and to promote nuclear localization (1).

In most untransformed cell types, NF- $\kappa \mathrm{B}$ complexes are largely cytoplasmic and therefore remain transcriptionally inactive until a cell receives an appropriate stimulus. In response to bacterial LPS, or proinflammatory cytokines such as TNF and IL-1, the IKB proteins become phosphorylated on two serine residues located within the $\mathrm{NH}_{2}$-terminal region (1). Phosphorylation of the IKB proteins results in rapid ubiquitination and subsequent proteolysis by the $26 \mathrm{~S}$ proteasome. Proteasome-dependent degradation of the IкB proteins results in the liberation of NF- $\mathrm{KB}$, allowing this transcription factor to accumulate in the nucleus where it activates the expression of specific genes (1) involved in immune and inflammatory responses and in cell growth control. Recently, a large-molecular weight complex was identified that is responsible for phosphorylating I $\mathrm{I} B \alpha$ and I $\mathrm{I} B \beta$. Two key catalytic subunits of the IKB kinase (IKK) complex were identified as IKK $\alpha$ and IKK $\beta$ (reviewed in ref. 2). In addition to signals that promote its accumulation in the nucleus, NF- $\kappa B$ is controlled at the level of its transcriptional activity by phosphorylation of its subunits (3). This modification establishes a second level of control of $\mathrm{NF}-\kappa \mathrm{B}$ function, governing its intrinsic capacity as a transactivator rather than its subcellular localization.

\section{$\mathrm{NF}-\mathrm{KB}$ expression and oncogenesis}

Evidence for the involvement of NF- $\mathrm{KB}$ in oncogenesis is not new. The earliest support for this idea came from work with retroviruses that encode v-Rel, a highly oncogenic viral homologue of c-Rel that causes aggressive tumors in chickens (reviewed in refs. 4, 5). Presumably more relevant to human cancer, the genes that encode c-Rel, NF- $\mathrm{KB} 2$ (p100/p52), and Bcl-3 proteins are located within regions of the genome that are involved in rearrangements or amplifications. Thus, the $c$-Rel gene has been found amplified in some cancer cell lines and rearranged in others $(4,5)$. The $B c l-3$ gene was identified as a $[\mathrm{t}(14,19)$ (q32; $\mathrm{q} 13.1)]$ chromosomal translocation in a subset of B-cell chronic lymphocytic leukemias (6) and is overexpressed in certain B-cell neoplasms $(6)$. The $t(10,14)$ chromosomal translocation breakpoint associated with NF- $\mathrm{KB} 2$ was originally found in a case of B-cell non-Hodgkin's lymphoma and occurs in a number of lymphoid neoplasms, particularly cutaneous lymphomas (7). Additionally, expression of lymphoma-associated p52 enhances the tumorigenic potential in $3 \mathrm{~T} 3$ cells in a SCID mouse system (8). Similarly, mice with a homozygous deletion of the $\mathrm{COOH}$-terminal ankyrin repeats of the p100 precursor (not found in the mature p52 protein) exhibit increased lymphocyte proliferation and gastric hyperplasia (9). Mutations in the $I \kappa B \alpha$ gene have been detected in Hodgkin's lymphoma (10) and are suggested to render NF- $\mathrm{KB}$ constitutively active in Hodgkin's cells, consistent with a role for $\mathrm{I} \kappa \mathrm{B}$ as a tumor suppressor.

Other compelling evidence links NF- $\kappa B$ with cellular transformation independent of chromosomal translocation events. Thus, NF- $\mathrm{KB}$ is activated by a number of viral transforming proteins and, in some cases, is required for virus-induced transformation. For example, the Tax protein from the human T-cell leukemia virus-I (HTLV-I) transcriptionally activates NF- $\kappa B$ (Hiscott et al., this Perspective series, ref. 11). It appears that 


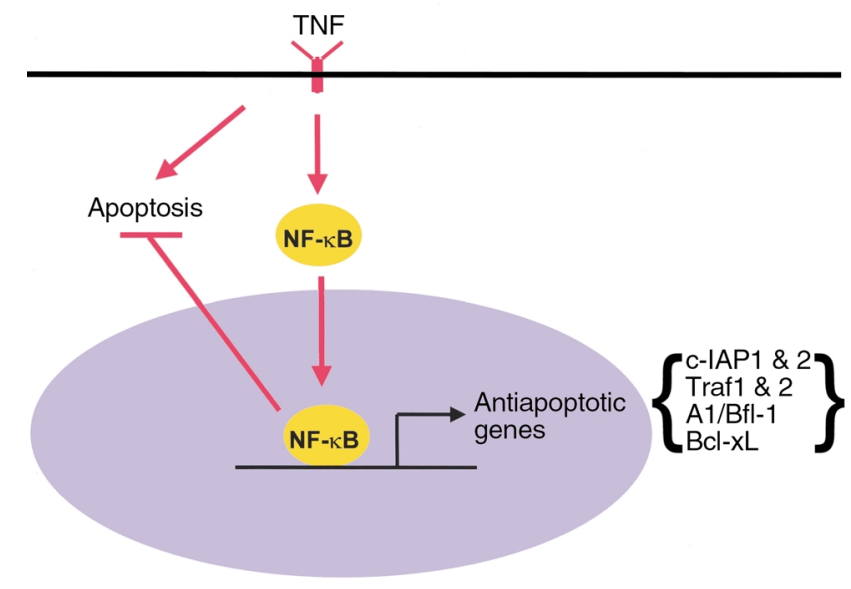

Figure 1

Induction of NF-KB by TNF or other stimuli leads to the transcriptional activation of genes that suppress apoptosis. The proteins encoded by the genes function at different levels in the caspase cascade to block apoptosis.

Tax activates NF- $\kappa \mathrm{B}$ through direct interactions with the IKK complex (12) and that activation of NF- $\kappa B$ is required for transformation of rat fibroblasts by Tax (13). Other viral transforming proteins, such as the Epstein-Barr virus-encoded (EBV-encoded) proteins, EBV protein nuclear antigen 2, the latent membrane protein 1 (LMP-1), the Simian virus-40-encoded Large$\mathrm{T}$, and adenovirus-encoded $\mathrm{E} 1 \mathrm{~A}$, all stimulate $\mathrm{NF}-\kappa \mathrm{B}$ transcriptional activity (14). Consistent with a role for this pathway in transformation and tumorigenesis, many human solid tumor cell lines display increased

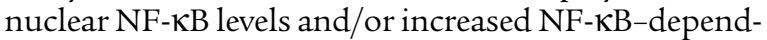
ent reporter expression.

Further support for the involvement of NF- $\mathrm{KB}$ in oncogenesis comes from experiments in which the NF- $\mathrm{NB}$ pathway has been directly perturbed. Inhibition of $\mathrm{NF}-\kappa \mathrm{B}$ by expression of a modified form of $\mathrm{I} \kappa \mathrm{B} \alpha$ (superrepressor $\mathrm{I} \kappa \mathrm{B} \alpha)(15)$ or by a dominant negative form of IKK (16) blocks focus formation induced by Ras. Tumorigenesis driven by the oncogenic fusion protein BCR-ABL, which activates NF- $\mathrm{BB}$, is also blocked by super-repressor $\mathrm{I} \kappa \mathrm{B} \alpha(17)$. NF- $\kappa \mathrm{B}$ is activated in Hodgkin's lymphoma (18) (and in a variety of transformed cell lines), and inhibition of NF- $\mathrm{KB}$ blocks growth of these lymphoma cells (18). Van Waes and colleagues (19) recently blocked NF- $\kappa B$ function in head and neck squamous cell carcinoma cells and showed that this inhibited xenograftderived tumor growth. Sovak et al. (20) reported that the classic form of NF- $\mathrm{BB}$ (p50-p65) is localized to the nucleus in breast cancer cell lines and in some breast tumors (20). Our observations agree that NF- $\kappa \mathrm{B}$ appears to be dysregulated in breast cancer, but we find that human breast tumors display an accumulation of nuclear p52 and $\mathrm{Bcl}-3$ along with $\mathrm{c}-\mathrm{Rel}$, rather than consistent activation of p65 (21). Presumably Bcl-3 promotes transcriptional activity through interactions with $\mathrm{p} 52$.
Regulation of NF-KB by oncoproteins

Early research on the regulation of NF- $\kappa B$ by activated cellular oncoproteins involved studies on Ras and Raf. NF- $\kappa B$ nuclear levels in Ras- or Raf-transformed fibroblasts are not significantly higher than in parental fibroblast cell lines, but NF- $\mathrm{BB}$-dependent reporter expression is nevertheless strongly elevated (15). This enigma was explained by showing that both Raf- and Ras-transformed cells display enhanced NF- $\kappa \mathrm{B}$ transcriptional activity through the ability of these oncoproteins to stimulate the inherent transcription function of the p 65 subunit of NF- $\kappa \mathrm{B}$ without strongly affecting $\mathrm{p} 65$ nuclear accumulation $(15,22)$. Surprisingly, dominant negative forms of Raf do not strongly inhibit the ability of Ras to activate NF- $\mathrm{KB}-$ dependent transcription (22).

Several observations may help explain the Raf-independent and Raf-dependent activation of NF- $\kappa \mathrm{B}$ by Ras. First, small molecule inhibitors of the stress-activated kinase p38 block the ability of Ras or Raf to activate the transcription function NF- $\mathrm{B}$ (22). However, p38 activation typically is found on a signal transduction pathway downstream of Ras, not Raf. This enigma was explained by data indicating that the ability of Raf to activate NF- $\kappa B$ involves the secretion of an autocrine factor that stimulates NF- $\kappa \mathrm{B}$ transcriptional activity in a manner similar to the p38-dependent mechanism used by Ras (22). Second, the serine/threonine kinase Akt/PKB is activated by Ras and this kinase can induce the transcriptional activity of the p65 subunit of NF- $\kappa B$ (23). Using rat liver epithelial cells, Sonenshein and colleagues show that Ras as well as Raf transformation led to enhanced I $\kappa \mathrm{B} \alpha$ degradation and elevated NF- $\mathrm{KB}$ DNA binding activity that are dependent on IKK activity (16).

Other oncogene products are known to activate NF- $\kappa$ B. As described above, HTLV-I Tax activates NF- $\kappa \mathrm{B}$ at least partly through binding to IKK and stimulating nuclear translocation of NF- $\kappa \mathrm{B}$. Her2/Neu, which is amplified and active in a significant proportion of breast cancer, stimulates the protein kinase Akt and thereby activates NF- $\kappa \mathrm{B}$-dependent gene expression (24). The BCR-ABL fusion oncoprotein, involved in chronic myelogenous leukemia, activates NF- $\mathrm{KB}$ by stimulating its nuclear translocation and also by enhancing its transactivation function (17).

\section{Antiapoptotic and pro-proliferative roles for NF-KB in oncogenesis}

Numerous studies have indicated that NF- $\kappa \mathrm{B}$ activation can suppress cell death pathways and that NF- $\kappa \mathrm{B}$ activation is required to protect cells from the apoptotic cascade induced by TNF and other stimuli (see ref. 25). NF- $\mathrm{KB}$ suppression of apoptosis appears to be a transcriptional event since it activates expression of TRAF 1 and 2 and c-IAP 1 and 2 to block caspase- 8 activation (Figure 1). Other antiapoptotic genes that are transcriptionally activated by NF- $\mathrm{KB}$ (Figure 1 ) include 
the Bcl-2 homologues A1/Bfl-1 and Bcl-xL, IEX-1, and XIAP. Of potential interest regarding inhibition of apoptosis is the observation that NF- $\mathrm{KB}$ can antagonize p53 function, possibly through the cross-competition for transcriptional coactivators (26). Conversely, as discussed below, $\mathrm{p} 53$ may in some cases act through $\mathrm{NF}-\kappa \mathrm{B}$ to induce apoptosis.

It has long been speculated that oncogenesis is associated with antiapoptotic mechanisms. We therefore asked whether one mechanism whereby NF- $\mathrm{KB}$ functions to promote oncogenesis was to suppress a transformation-associated apoptosis. We found that inhibition of NF- $\mathrm{KB}$, via the expression of the super-repressor form of $I \kappa B \alpha$, leads to the induction of apoptosis when an oncogenic allele of $\mathrm{H}$-Ras (RasV12) is expressed (27). Other evidence has been presented that NF- $\mathrm{KB}$ plays a survival role in oncogenesis since inhibition of NF- $\mathrm{KB}$ in transformed cells can induce apoptosis (see ref. 20). In addition, the EBV protein LMP-1 activates NF- $\kappa B$ (see Hiscott et al., this Perspective series, ref. 11), suppressing apoptosis in EBV-transformed cells (28). Activation of NF- $\kappa \mathrm{B}$ by growth factors also suppresses the apoptotic response induced by c-myc expression (29), although it is unclear which of the antiapoptotic mechanisms that are regulated by NF- $\kappa B$ perform this function. Additionally, members of the IAP family of antiapoptotic proteins are upregulated in a variety of cancers, possibly by the NF-KB pathway.

In addition to being required to suppress transformation-induced apoptosis, NF- $\mathrm{KB}$ can promote cell growth by upregulating transcription of cyclin D1, an event that is associated with Rb hyperphosphorylation, progression into the $S$ phase of the cell cycle, and inhibition of apoptosis (Figure 2). Importantly, cyclin D1 is upregulated in a number of human tumors. In light of its potent effects on cell survival and growth, NF- $\kappa B$ may be found to control other aspects of cell cycle progression as well.

\section{$\mathrm{NF}-\mathrm{KB}$ in other aspects of tumor progression}

Gene regulation by NF- $\kappa B$ is presumed to control its major oncogenic functions, as in the case of cyclin D1 and in the antiapoptotic response, noted above, that blocks the ability of oncogenic Ras to induce apoptosis. Other NF-KB-regulated gene products that contribute to oncogenesis may include tenascin-C, an ECM protein involved in cell attachment and cell growth. NF- $\mathrm{KB}$ also regulates ICAM-1 (1), a cell adhesion molecule found expressed in about $70 \%$ of primary melanoma lesions and in about $90 \%$ of metastatic melanomas. ICAM-1 expression is associated with a poor prognosis and reduced disease-free intervals. Cox-2, a protein involved in inflammation and angiogenesis, is found upregulated in more aggressive forms of colorectal cancer and is transcriptionally activated by NF- $\kappa B$ (1). The upregulation of inducible nitric oxide synthase and the enhanced production of nitric oxide has also been proposed to enhance tumor progression and angiogenesis. NF- $\mathrm{KB}$ has also been shown to induce expression of the c-myc and c-myb proto-oncogenes and of gro $\alpha$ (melanoma stimulatory factor, which is implicated in angiogenesis). Finally, hypoxia in regions of malignant tumors is thought to influence tumor progression by activating angiogenesis. Since hypoxia/reperfusion can induce NF- $\mathrm{KB}$ activation, this pathway may contribute to a pro-malignant phenotype not only by promoting cell proliferation and survival, but also by upregulating gene products that control cell adhesion and angiogenesis.

\section{Figure 2}

Roles of NF- $\mathrm{KB}$ in oncogenesis and in cancer chemoand radioresistance. Activation of NF- $\mathrm{KB}$ blocks apoptosis, induces cell proliferation, potentially blocks differentiation, and promotes metastasis.

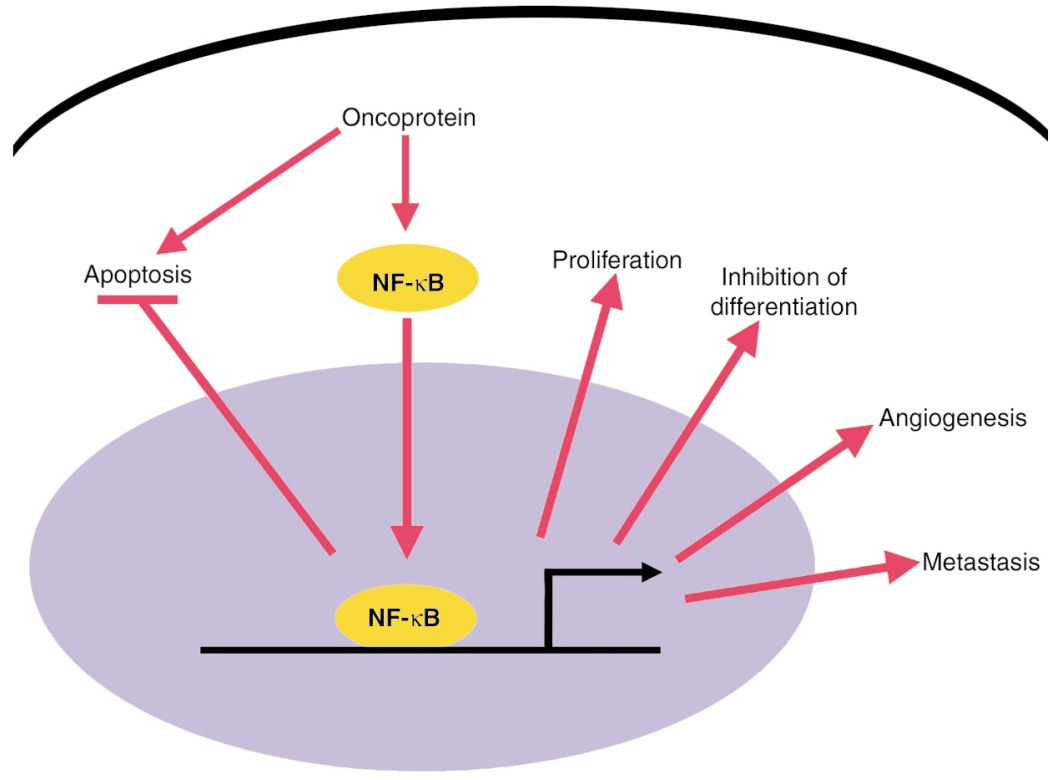


NF-KB-dependent regulation of cell adhesion molecules (1) and cell surface proteases (such as matrix metalloproteinase 9) (30) raises the possibility that NF- $\mathrm{KB}$ can control metastasis. This idea is supported by the findings that $\mathrm{Cdc} 42$ and Rac induce integrin-mediated invasiveness through PI 3-kinase (PI3K) (31) and that $\mathrm{Rac}$ and PI3K can activate NF- $\kappa \mathrm{B}$. Consistent with these points, the finding that IKB $\alpha$ expression in tumor cells decreases the frequency of metastases suggests that the NF- $\mathrm{KB}$ pathway can promote metastasis (32).

\section{Potential antioncogenic and proapoptotic mechanisms for NF-kB}

Although NF- $\kappa B$ clearly participates in many aspects of oncogenesis, both by promoting cell growth and blocking apoptosis, other evidence in the literature indicates that NF- $\mathrm{KB}$ activity can in some cases prevent oncogenesis and promote apoptosis. Thus, von Hogerlinden et al. have noted that inhibition of NF- $\mathrm{KB}$ in the skin via expression of the super-repressor form of I $\mathrm{I} B \alpha$ can lead to squamous cell carcinomas, as well as increased apoptosis (33). Since NF-KB and IKK $\alpha$ have been proposed to control skin differentiation $(2,34)$, the loss of some form of NF- $\kappa B$ may promote oncogenesis in this setting. However, the activation of NF- $\mathrm{KB}$ seen in breast cancer generally is not the p50-p65 heterodimer but rather complexes that contain $\mathrm{p} 50$, p52, and $\mathrm{Bcl}-3$ (21). It is presently assumed that the nuclear accumulation of $\mathrm{Bcl}-3$ is independent of inhibition by other IKB proteins and of IKK stimulation. Thus, IКB expression does not generate a true NF- $\mathrm{KB}$ null phenotype and may, in fact, lead to the upregulation of functionally different NF- $\mathrm{KB}$ complexes. Therefore, different NF- $\kappa B$ complexes (some lacking p65) may control growth and differentiation in different cell types or in response to different stimuli. In this regard, it is interesting to speculate that there are opposing roles for NF- $\mathrm{\kappa B}$ subunits in transformation.

Despite the strong evidence for NF- $\mathrm{KB}$ as an antiapoptotic factor, there are cases in which NF- $\mathrm{KB}$ appears to function proapoptotically. For example, Kasibhatla et al. $(35,36)$ have provided evidence that NF- $\mathrm{KB}$ and AP-1 induce the proapoptotic Fas ligand (FasL) protein in response to chemotherapeutic agents or T-cell activation signals. In these studies, T cells can be induced, through the NF- $\mathrm{KB}$-dependent upregulation of FasL, to undergo apoptosis in response to etoposide or T-cell activation signals. Thus, the inhibition of NF- $\mathrm{KB}$ provided cell protection from genotoxically induced or T-cell activation-induced Fas-directed death signaling. Consistent with the dysregulated NF- $\kappa \mathrm{B}$ transcriptional activity in human cancers, some transformed cells derived from solid tumors display constitutive FasL expression. It should be noted that Sun and colleagues have questioned whether NF- $\mathrm{KB}$ regulates FasL transcription (37).

Recently, different groups have described both antagonistic and interdependent roles for the tumor sup- pressor protein $\mathrm{p} 53$ and NF- $\mathrm{KB}$. Direct antagonism between these proteins (26) is consistent with the established antiapoptotic role of NF- $\mathrm{KB}$ and the proapoptotic role of $\mathrm{p} 53$. However, there is evidence that NF- $\mathrm{KB}$ can regulate $\mathrm{p} 53$ expression and that NF- $\mathrm{KB}$ is required for p53 to induce cell death (38). Clearly, a better understanding of the relationships between p53 and $\mathrm{NF}-\mathrm{\kappa B}$ in general, as well as specific NF- $\mathrm{KB}$ subunits, is required to elucidate the range of effects of these regulators on cell proliferation and death.

\section{Preventing and treating cancer by NF-KB \\ inhibition: promise and complications}

Evidence that inhibition of NF- $\mathrm{KB}$ in cells induced to express an oncogenic form of Ras or in some cancer cell lines led to an apoptotic response (27) raised the possibility that inhibitors of NF- $\kappa B$ may function as stand-alone cancer therapies or as cancer-preventive compounds. Regarding the first hypothesis, it is generally assumed that inhibition of NF- $\mathrm{KB}$ alone will not dramatically affect most solid tumors, since they express other antiapoptotic factors. However, NF- $\kappa B$ inhibition may prove to be therapeutic in certain leukemias or lymphomas (such as Hodgkin's lymphoma), where NF- $\mathrm{KB}$ appears to play a unique survival role (18). Consistent with the hypothesis that NF- $\kappa B$ may be an important target for chemopreventive compounds, NF- $\mathrm{KB}$ is inhibited by aspirin or other nonsteroidal anti-inflammatory drug (NSAID) treatments (see Yamamoto and Gaynor, this Perspective series, ref. 39), which block the initiation and/or progression of certain cancers, particularly colorectal cancer. Interestingly, aspirin and sulindac both have been reported to inhibit the activation of the IкB kinase complex (39). Several dietary chemopreventive compounds, including flavonoids, curcumin, and resveratrol, are known to block NF- $\kappa B$ activation (39, 40). These studies strongly support the hypothesis that NF- $\kappa \mathrm{B}$ is a functionally relevant target of chemopreventive drugs and dietary compounds, possibly indicating that the role of NF- $\mathrm{KB}$ is primarily in the earliest stages of oncogenesis.

The demonstration that NF- $\mathrm{KB}$ can inhibit apoptosis led us to examine whether NF- $\kappa B$ renders tumors resistant to chemotherapies and radiation. Working with HT1080 fibrosarcoma cells exposed to ionizing radiation or to the chemotherapeutic agent daunorubicin, we found that these treatments induce strong nuclear accumulation of the NF- $\kappa B$ p50-p65 heterodimer (41). Inhibition of NF- $\kappa \mathrm{B}$ by expression of the super-repressor form of I $\kappa \mathrm{B} \alpha$ dramatically improves the apoptotic response to ionizing radiation or daunorubicin. HT1080 fibrosarcoma-derived tumors grown in nude mice are resistant to the drug CPT-11 but can be induced to undergo apoptosis following treatment if they are infected with an adenovirus expressing the modified form of IKB $\alpha$ (42). Other tumors (for exam- 
ple, those derived from the colorectal tumor cell line LoVo) showed nearly identical responses to the combined treatment. In fact, LoVo tumors could be eliminated with CPT-11 systemic treatment and with adenoviral delivery of IKB $\alpha$ either every 5 or 10 days $(42,43)$. Importantly, the systemic use of inhibitors of NF- $\mathrm{KB}$ in conjunction with CPT-11 treatment also led to significantly improved chemotherapeutic responses through enhanced apoptosis (J. Cusack et al., unpublished results; and see Yamamoto and Gaynor, this Perspective series, ref. 39). Other issues regarding chemotherapy and NF- $\mathrm{KB}$ activation are summarized in ref. 44.

The form of chemotherapy used may determine whether NF- $\mathrm{KB}$ is pro- or antiapoptotic. For example, the majority of chemotherapies that we have studied induce some form of DNA damage; inhibition of NF- $\kappa B$ activation, conversely, promotes cell death. However, it was reported recently that NF- $\kappa B$ may be required for cell death induced by the microtubulebinding agent Taxol (45), which does not affect DNA stability, but engages the mitotic spindle checkpoint. In light of evidence from another group showing that NF-KB inhibition can enhance Taxol-induced cell death (46), it is clear that more studies will be needed to define the effects of NF- $\mathrm{KB}$ on the efficacy of different chemotherapies for specific classes of tumor.

\section{Summary}

The abilities of NF- $\mathrm{KB}$ to promote cell proliferation, suppress apoptosis, promote cell migration, and suppress differentiation apparently have been co-opted by cellular and viral oncoproteins to promote oncogenesis (Figure 2). Direct evidence, using both in vitro and in vivo models, indicates that NF- $\mathrm{KB}$ is required for oncogenesis, probably at multiple levels. NF- $\mathrm{KB}$ likely plays an important role in the early events of oncogenesis, possibly functioning primarily in protecting against transformation-associated apoptosis. In most late-stage tumor cells, classic NF- $\mathrm{kB}$ (the p50-p65 heterodimer) is clearly not the only survival factor, because its inhibition does not induce apoptosis in many of these tumor cells. This observation suggests that other events have occurred to upregulate NF- $\mathrm{KB}$-independent cell survival pathways. However, clearly some cancer cells depend on NF- $\kappa B$ for their survival. NF- $\kappa B$ also can contribute to cell progression by transcriptionally upregulating cyclin D1 with corresponding hyperphosphorylation of the tumor suppressor protein $\mathrm{Rb}$. The induction of NF- $\mathrm{\kappa B}-$ controlled proliferation may correlate with loss of differentiation in certain settings (47), which may promote oncogenesis. NF- $\mathrm{KB}$ is known to regulate certain genes associated with metastasis, such as matrix metalloproteinase 9, tissue plasminogen activator, and ICAM- 1 . Thus, a more relevant role for NF- $\mathrm{KB}$ in later-stage oncogenesis may be to promote metastasis and angiogenesis. Although many tumor cells display some level of constitutive nuclear
$\mathrm{NF}-\kappa \mathrm{B}$, higher levels of NF- $\mathrm{KB}$ and the transcriptional potential of NF- $\kappa B$ can be further enhanced in response to certain types of chemotherapy. Consistent with this, inhibition of NF- $\mathrm{BB}$ in parallel with certain (but apparently not all) chemotherapy treatments strongly enhances the apoptotic potential of the chemotherapy. This observation indicates that NF- $\mathrm{KB}$ plays an important role in inducible chemoresistance and establishes NF- $\mathrm{KB}$ inhibition as a new adjuvant approach in chemotherapy.

\section{Acknowledgments}

Research supporting work in my laboratory has been provided by the NIH and the National Cancer Institute as well as the Leukemia and Lymphoma Society. I gratefully acknowledge Denis Guttridge for preparation of the figures. Due to editorial limitation of referencing, a number of relevant articles could not be cited in this review.

1. Ghosh, S., May, M., and Kopp, E. 1998. NF-кB and Rel proteins: evolutionarily conserved mediators of immune respones. Annu. Rev. Immunol. 16:225-260.

2. Zandi, E., and Karin, M. 1999. Bridging the gap: composition, regulation, and physiological function of the IкB kinase complex. Mol. Cell. Biol. 19:4547-4551.

3. Zhong, H., Voll, R., and Ghosh, S. 1998. Phosphorylation of NF- $\kappa B$ p 65 by PKA stimulates transcriptional activity by promoting a novel bivalent interaction with the co-activator CBP/p300. Mol. Cell. 1:661-671.

4. Gilmore, T., Koedood, M., Piffat, K., and White, D. 1996. Rel/NF-кB/ІкB proteins and cancer. Oncogene. 13:1367-1378.

5. Rayet, B., and Gelinas, C. 1999. Aberrant Rel/NF- $\mathrm{kB}$ genes and activity in human cancer. Oncogene. 18:6938-6947.

6. McKeithan, T., et al. 1997. Bcl-3 rearrangements and $t(14 ; 19)$ in chronic lymphocytic leukemia and other B-cell malignancies: a molecular and cytogenetic study. Genes Chromosomes Cancer. 20:64-72.

7. Fracchiolla, N., et al. 1993. Stuctural alterations of NF- $\kappa B$ transcription factor lyt-10 in lymphoid malignancies. Oncogene. 8:2839-2845.

8. Ciana, P., et al. 1997. Constitutive expression of lymphoma-associated NF$\kappa \mathrm{B} 2 /$ lyt-10 proteins is tumorigenic in murine fibroblasts. Oncogene. 14:1805-1820.

9. Ishikawa, H., Carrasco, D., Claudio, E., Ryseck, R.-P., and Bravo, R. 1997. Gastric hyperplasia and increased proliferative responses of lymphocytes in mice lacking the C-terminal ankyrin domain of NF-кB2. J. Exp. Med. 186:999-1014.

10. Cabannes, E., Khan, G., Aillet, F., Jarrett, R., and Hay, R. 1999. Mutations in the I $\kappa \mathrm{B} \alpha$ gene in Hodgkin's disease suggest a tumor suppressor role for IкB $\alpha$. Oncogene. 18:3063-3070.

11. Hiscott, J., Kwon, H., and Génin, P. 2001. Hostile takeovers: viral appropriation of the NF-kB pathway. J. Clin. Invest. 107:143-151.

12. Chu, Z., DiDonato, J., Hawiger, J., and Ballard, D. 1998. The Tax oncoprotein of HTLV-I associates with and persistently activates I $\mathrm{KB}$ kinases containing IKK $\alpha$ and IKKß. J. Biol. Chem. 273:15891-15894.

13. Yamaoka, S., et al. 1996. Constitutive activation of NF- $\kappa B$ is essential for transformation of rat fibroblasts by HTVL-I Tax protein. EMBO J. 15:873-887.

14. Mosialos, G. 1997. The role of Rel/NF- $\mathrm{kB}$ proteins in viral oncogenesis and regulation of viral transcription. Semin. Cancer Biol. 8:121-129.

15. Finco, T., et al. 1997. Oncogenic Ha-Ras-induced signaling activates NF$\kappa \mathrm{B}$ transcriptional activity which is required for cellular transformation. J. Biol. Chem. 272:24113-14116.

16. Arsura, M., Mercurio, F., Oliver, A., Thorgeirsson, S., and Sonenshein, G. 2000. Role of IKB complex in oncogenic Ras- and Raf-mediated transformation of rat liver epithelial cells. Mol. Cell. Biol. 20:5381-5391.

17. Reuther, J., Reuther, G., Cortez, D., Pendergast, A.M., and Baldwin, A. 1998. A requirement for NF- $\kappa B$ activation in Bcr-Abl-mediated transformation. Genes Dev. 12:968-981.

18. Bargou, R., et al. 1997. Constitutive activation of NF- $\kappa B-R e l A$ is required for proliferation and survival of Hodgkin's disease tumor cells. J. Clin. 
Invest. 100:2961-2969.

19. Duffey, D., et al. 1999. Expression of a dominant negative mutant inhibitor of NF- $\mathrm{KB}$ in human head and neck squamous cell carcinoma inhibits survival, proinflammatory cytokine expression and tumor growth in vivo. Cancer Res. 59:3468-3474.

20. Sovak, M., et al. 1997. Aberrant NF-kB/Rel expression and pathogenesis of breast cancer. J. Clin. Invest. 100:2952-2960.

21. Cogswell, P., Guttridge, D., Funkhouser, W., and Baldwin, A. 2000. Selective activation of NF- $\mathrm{KB}$ subunits in human breast cancer: potential roles for NF-kB2/p52 and for Bcl-3. Oncogene. 19:1123-1131.

22. Norris, J., and Baldwin, A. 1999. Oncogenic Ras enhances NF- $\kappa B$ transcriptional activity through Raf-dependent and Raf-independent mitogen-activated protein kinase signaling pathways. J. Biol. Chem. 274:13841-13846.

23. Madrid, L., et al. 2000. Akt suppresses apoptosis by stimulating the transcriptional activation potential of the RelA/p 65 subunit of NF- $\mathrm{KB} . \mathrm{Mol}$. Cell. Biol. 20:1626-1638.

24. Zhou, B., et al. 2000. Her-2/Neu blocks TNF-induced apoptosis by stimulating the transactivational potential of the RelA/p 65 subunit of NF- $\mathrm{KB}$. J. Biol. Chem. 275:8027-8031.

25. Barkett, M., and Gilmore, T. 1999. Control of apoptosis by Rel/NF- $\mathrm{BB}$ transcription factors. Oncogene. 18:6910-6924.

26. Webster, G., and Perkins, N. 1999. Transcriptional cross-talk between NF$\kappa \mathrm{B}$ and $\mathrm{p53}$. Mol. Cell. Biol. 19:3485-3495.

27. Mayo, M., et al. 1997. Requirement of NF- $\mathrm{KB}$ activation to suppress p53independent apoptosis induced by oncogenic Ras. Science. 278:1812-1815.

28. Cahir-McFarland, E., Davidson, D., Schauer, S., Duong, J., and Kieff, E. 2000. NF-кB inhibition causes spontaneous apoptosis in Epstein-Barr virus-transformed lymphoblastoid cells. Proc. Natl. Acad. Sci. USA. 97:6055-6060.

29. Romashkova, J., and Makarov, S. 1999. NF- $\kappa$ B is a target of Akt in antiapoptotic PDGF signaling. Nature. 401:86-89.

30. Takeshita, H., et al. 1999. Matrix metalloproteinase 9 expression is induced by Epstein-Barr virus latent membrane protein $1 \mathrm{C}$-terminal activation regions 1 and 2. J. Virol. 73:5548-5555.

31. Keely, P., Westwick, J., Whitehead, I., Der, C., and Parise, L. 1997. Cdc42 and Rac1 induce integrin-mediated cell motility and invasiveness through PI(3)K. Nature. 390:632-636.

32. Huang, S., DeGuzman, A., Bucana, C., and Fidler, I. 2000. NF-кB activity correlates with growth, angiogenesis, and metastasis of human melanoma cells in nude mice. Clin. Cancer Res. 6:2573-2581.

33. von Hogerlinden, M., Rozell, B., Ahrlund-Richter, L., and Toftgard, R. 1999. Squamous cell carcinoma and increased apoptosis in skin with inhibited Rel/NF-אB signaling. Cancer Res. 59:3299-3303.

34. Seitz, C., Lin, Q., Deng, H., and Khavari, P. 1998. Alterations in NF-кB function in transgenic epithelial tissues demonstrate a growth inhibitory role for NF-kB. Proc. Natl. Acad. Sci. USA. 95:2307-2312.

35. Kasibhatla, S., Genestier, L., and Green, D. 1999. Regulation of Fas-ligand expression during activation-induced cell death of Tlymphocytes via NFкB. J. Biol. Chem. 274:987-992.

36. Kasibhatla, S., et al. 1998. DNA damaging agents induce expression of Fas ligand and subsequent apoptosis in T lymphocytes via the activation of NF- $\kappa$ B and AP-1. Mol. Cell. 1:543-551.

37. Rivera-Walsh, I., Cvijic, M., Xiao, G., and Sun, S. 2000. The NF-kB signaling pathway is not required for Fas ligand gene induction but mediates protection from activation-induced cell death. J. Biol. Chem. 275:25222-25230

38. Ryan, K., Ernst, M., Rice, N., and Vousden, K. 2000. Role of NF- $\kappa B$ in p53mediated programmed cell death. Nature. 404:892-897.

39. Yamamoto, Y., and Gaynor, R.B. 2001. Therapeutic potential of inhibition of the NF- $\mathrm{kB}$ pathway in the treatment of inflammation and cancer.J. Clin. Invest. 107:135-142.

40. Holmes-McNary, M., and Baldwin, A. 2000. Chemopreventive properties of trans-resveratrol are associated with inhibition of activation of I $\mathrm{KB}$ kinase. Cancer Res. 60:3477-3483.

41. Wang, C.-Y., Mayo, M., and Baldwin, A. 1996. TNF- and cancer therapyinduced apoptosis: potentiation by inhibition of NF-KB. Science. 274:784-787.

42. Wang, C.-Y., Cusack, J., Liu, R., and Baldwin, A. 1999. Control of inducible chemoresistance: enhanced anti-tumor therapy through increased apoptosis by inhibition of NF-KB. Nat. Med. 4:412-417.

43. Cusack, J., Liu, R., and Baldwin, A. 2000. Inducible chemoresistance to CPT-11 in colorectal cancer cells and a xenograft model is overcome by inhibition of NF-KB. Cancer Res. 60:1323-1330.

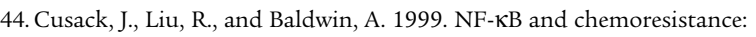
potentiation of cancer chemotherapy via inhibition of NF-אB. Drug Resistance Updates. 2:271-273.

45. Huang, Y., Johnson, K., Norris, J., and Fan, W. 2000. NF-кB/IкB signaling pathway may contribute to the mediation of paclitaxel-induced apoptosis in solid tumor cells. Cancer Res. 60:4426-4432.

46. Natel, N., et al. 2000. Paclitaxel sensitivity in breast cancer cells with constitutively active NF- $\kappa \mathrm{B}$ is enhanced by $\mathrm{I} \kappa \mathrm{B} \alpha$ super-repressor and parthenolide. Oncogene. 19:4159-4169.

47. Guttridge, D., Mayo, M., Madrid, L., Wang, C.-Y., and Baldwin, A. 2000. $\mathrm{NF}-\mathrm{KB}$ induced loss of MyoD mRNA: possible role in muscle decay and cachexia. Science. 289:2363-2366. 